\title{
Defecation in stressful and non-stressful situations
}

\author{
Gardmer Lindzey, Harvey D. Winston and Glayde D. Whitney \\ UNIVERSITY OF MINNESOTA
}

\begin{abstract}
If individual and strain differences in open-field defecation reflect a stable alimentary trait that is not indicative of response to stress, the rate of defecation in the open-field situation should be correlated with defecation in the home cage. This association was tested for 106 mice representing four different genotypes. The evidence indicates that home cage defecation rate has little association with open-field performance. Moreover, the relation between these two indices appears to vary with genotype.
\end{abstract}

\section{Problem}

The variable of emotionality or fearfulness as measured by open-field defecation is one of the most extensively studied attributes in the domain of animal temperament (Broadhurst, 1960; Hall, 1941). It has been shown to relate to a variety of antecedent and concomitant events including genotype (Broadhurst, 1960; Hall, 1938; Lindzey, 1951). On the other hand, there have been many objections to the measure (Bindra \& Thompson, 1953; Hunt \& Otis, 1953; O'Kelly, 1940; Tobach \& Schneirla, 1962). One complaint frequently encountered is that the measure may reflect differences in digestive-tract function and might be observed just as readily in a familiar or nonstressful situation as in the open field.

If this hypothesis is correct, some of the results that have been reported could be assigned to variation in the ingestion, digestion and elimination of food rather than to differences in response to stressful situations or in fearfulness. A simple test of this hypothesis can be made by comparing the defecation of animals in the open-field situation with that in their familiar home cage.

\section{Subjeets}

The Ss of this investigation were 106 mice drawn from three inbred strains (A, C57/B1/1, $\mathrm{DBA} / 8$ ) and from the $\mathrm{F}_{.2}$ generation of a cross between the $\mathrm{A}$ and the DBA/8 strains. Ss were weaned at. 22 days of age and were housed at approximately 45 days in individual cages with

1

This research was supported by a grant from the Ford Foundation and by research Grant M-3536 from the National Institute of Mental Health. wire mesh floors. All Ss were over 60 days of age at the time of testing, and the proportion of male and female Ss was approximately equal in the four groups.

\section{Procedure}

Each S was observed daily for two minutes on ten consecutive days in the open-field test and the incidence of defecation was recorded. The open-field test was administered in a\#1 twelvegallon washtub that was brightly illuminated by a shielded 150-watt glazed bulb placed directly over the tub at a height of 1.5 feet. During the same ten days, the incidence of defecation in the home cage for each 24-hour period was also recorded six hours before open-field testing. For each $\mathrm{S}$ the number of fecal boli defecated in the open field was totaled over ten days and the same operation was carried out with the fecal boli defecated in the home cage. The total scores for the two measures were then correlated by means of the product-moment correlation for each group and across all groups.

\section{Results}

Correlation coefficients summarizing the association within each strain between open-field and home-cage defecation are presented in Table 1. The two measures, clearly, assess relatively distinct attributes. The general correlation (grand correlation for all animals $\mathrm{r}=.09$; $\mathrm{n}=106$; average correlation across strains using a $\mathrm{Z}$ transformation, $\mathrm{r}=.04 ; \mathrm{n}=106$ ) is far lower than would be expected from similar indices of the same underlying variable. Indeed the correlations do not differ significantly from zero. In contrast, reliability coefficients for the open-field defecation measure (Broadhurst, 1960 ) generally run about .80. In our case, splithalf correlations computed over the ten trials for our two measures gave corrected reliabilities of .81 for the open-field measure and .93 for home-cage defecation. Using these figures to correct our inter-correlations for unreliability produces little effect. The overall $\mathrm{r}$ then becomes .10 and the average .07. Likewise, the correlations within strains remain inconsistent after correction for attenuation (Table 1). 
TABLE 1. Intercorrelation of Home Cage and Open Field Defecation in Mice

\begin{tabular}{lccc}
\multicolumn{1}{c}{ Strain } & N & \multicolumn{2}{c}{ Home Cage } \\
& & $\overrightarrow{\mathrm{X}}$ & $\mathrm{S}$ \\
$\mathrm{A}$ & 27 & 114.6 & 11.40 \\
$\mathrm{C} 57 / \mathrm{B} 1 / 1$ & 25 & 123.3 & 16.39 \\
$\mathrm{DBA} / 8$ & 27 & 141.2 & 12.27 \\
$\mathrm{~A} \mathrm{x} \mathrm{DBA} / 8\left(\mathrm{~F}_{2}\right)$ & 27 & 115.9 & 11.08
\end{tabular}

*Significant at $5 \%$ level

The lack of correlation between the two measures also appears in the ordering of strain differences. The order from high to low for the open-field measure as Table 1 indicates, is A, $\mathrm{DBA} / 8, \mathrm{~A} \times \mathrm{DBA} / 8\left(\mathrm{~F}_{2}\right), \mathrm{C} 57 / \mathrm{B} 1 / 1$. That for home-cage defecation is $\mathrm{DBA} / 8, \mathrm{C} 57 / \mathrm{B} 1 / 1$, A $x$ DBA $/ 8\left(F_{2}\right)$, A. These strain differences are significantly different $(p=.001)$ for both measures, thus confirming the results of earlier studies (see Lindzey et al., 1963).

Genetic differences also are evident when correlation coefficients between the two measures are computed strain by strain. These range from significantly negative (C57/B1/1) to significantly positive ( $F_{2}$ hybrids). Such differences are, of course, exaggerated when the correlations are corrected for attenuation (Table 1). They suggest that different genotypes may be associated with different organizations or structures of behavior traits. If firmly demonstrated, such a finding has important implications for personality theory and research.

The variation in the correlations for the different strains cannot be accounted for simply in terms of biological uniformity. The correlation for the $\mathrm{C} 57 / \mathrm{B} 1 / 1$ (inbred to 56 generations) is approximately the same in magnitude (although reversed in sign) as the $\mathrm{F}_{2}$ hybrids. Moreover, the standard deviations of the measures (Table 1) indicate that these hybrids are no more variable

\begin{tabular}{rccc}
\multicolumn{2}{c}{ Open } & Field & \multicolumn{2}{c}{$\mathrm{r}$} & $\mathrm{r}$ \\
$\mathrm{X}$ & $\mathrm{S}$ & \multicolumn{2}{c}{ (corrected) } \\
12.48 & 4.73 & .133 & .292 \\
4.76 & 3.95 & $-.386^{*}$ & -.511 \\
11.22 & 10.71 & .008 & .009 \\
5.44 & 5.45 & $.365^{*}$ & .445
\end{tabular}

in their performance than the three highly inbred strains in spite of the $\mathrm{F}_{2}$ 's greater genetic variability.

\section{References}

BINDRA, D. and THOMPSON, W. R. An evaluation of defecation and urination as measures of fearfulness. J. comp. physiol. Psychol., 1953, 46, 43-45.

BROADHURST, P. L. Experiments in psychogenetics. In Eysenck, H. J. (Ed.), Experiments in personality, Vol. 1. London: Routledge \& Kegan Paul, 1960. Pp. 1-102.

HALL, C. S. The inheritance of emotionality. Sigma Xi Quart., 1938, 26, 17-27.

HALL, C. S. Temperament: A survey of animal studies. Psychol. Bull., 1941, 38, 909-943.

HUNT, H. F. and OTIS, L. S. Conditioned and unconditioned emotional defecation in the rat.J. comp. physiol. Psychol., 1953, 46, 378-383.

LINDZEY; G. Emotionality and audiogenic seizure susceptibility in five inbred strains of mice. J.comp. physiol. Psychol., 1951, 44, 389-393.

LINDZEY, G., WINSTON, H. D., and MANOSEVITZ, M. Early experience, genotype and temperament in Mus musculus. J.comp. physiol. Psychol., 1963, 56, 622629.

O'KELLY, L. I. The validity of defecation as a measure of emotionality in the rat. J.gen.Psychol., 1940 $23,75-87$.

TOBACH,ETHEL and SCHNEIRLA, T. C. Eliminative responses in mice and rats and the problem of "emotionality." In Bliss, E. L. (Ed.), Roots of Behavior. New York: Hoeber, 1962. Pp. 211-231. 